\title{
Communicating COVID-19 Vaccine Safety: Knowledge and Attitude Among Residents of South East, Nigeria
}

\author{
Luke Ifeanyi Anorue (1D \\ Alphonsus Chukwuma Ugwu \\ Stanley Uzoamaka Ugboaja \\ Uzoma O Nwabunze \\ Chinyere Christiana Ugwulor- \\ Onyinyechi \\ Chioma Njoku
}

Department of Mass Communication, University of Nigeria, Nsukka, Nigeria
Background: The fight against the coronavirus disease (COVID-19), which has continued to threaten human existence globally, has led to the development of vaccines in order to control the rate of infection and death associated with the disease. Media messages on the COVID-19 vaccine are geared towards raising audience awareness and understanding of health risks, knowledge and attitudes about the vaccine safety.

Objective: The study examined the knowledge and attitude towards COVID-19 vaccine safety media messages amongst residents of South East, Nigeria.

Methods: A cross-sectional descriptive study was conducted among 399 respondents (1847 years) in both urban and rural communities of South East, Nigeria from May 6th to July 4th, 2021. The survey was carried out using structured self administered questionnaire containing the respondents' demographics, knowledge and attitudes towards media messages regarding COVID-19 vaccine safety. The data were analysed using the SPSS version 26 software. Result was presented in frequencies, percentages and charts showing the interrelatedness of the variables examined. Regression ANOVA was used to test hypotheses on the extent to which level of exposure to COVID-19 media messages predict their knowledge and attitude towards COVID-19 vaccine safety at $P<0.05$ level of significance.

Results: Data indicate respondents are apprehensive of taking the COVID-19 vaccine. Approximately, 91\% of respondents are between the ages of 18 and 27 years. Meanwhile, $26.1 \%$ of the respondents agreed that media messages on COVID-19 vaccine is very assuring and convincing as regards human safety; $42.4 \%$ disagreed on the safety of COVID-19 vaccine safety messages; $26.1 \%$ rated vaccine messages as moderate as regards human safety, while $5.5 \%$ rated the vaccine messages as poor. Knowledge of respondents regarding the safety of the vaccine was low and respondents' attitude was negative in South East, Nigeria. The implication is indicative of the failure of the main stream media in educating the general public on pertinent health issues relevant to them.

Conclusion: Knowledge regarding media messages on COVID-19 vaccine safety is low. Messages on COVID-19 vaccine safety were not sufficient and convincing. Consequently, there is a negative attitude towards the vaccine. Hence, improving knowledge and adoptive attitude amongst respondents amidst COVID-19 is critical.

Keywords: COVID-19, vaccine, safety, knowledge, attitude, media advocacies

\section{Introduction}

The challenges posed by the novel coronavirus pandemic since late 2019 till date are one of the worst health challenges recorded after the 1918-1920 flu pandemic that claimed over 100 million lives globally. ${ }^{1}$ Coronavirus (COVID-19) is an illness of severe Acute 
Respiratory Syndrome caused by a novel coronavirus ${ }^{2}$ and has become a major public health concern. ${ }^{3}$ The disease is transmitted through saliva and mucus droplets from an infected person. The symptoms of the COVID-19 infection are similar to that of other beta coronaviruses. ${ }^{4}$ Symptoms include fever, cough, dyspnea, weakness and fatigue, headache and diarrhea. ${ }^{5}$ COVID-19 disease is posing a great global public health threat in our world today since the first quarter of 2020. The catastrophic news of the Corona-virus, which has claimed thousands of lives around the world, has had a tsunami effect on every nation in the first quarter of 2020 , halting all global economies $^{6,7}$ without any notice or foresight from scientists and defying all scientific strength. Infected patients died at a higher rate, especially among the elderly who had underlying diseases such as cancer, diabetes, chronic respiratory disorders, acute cough, and so on. ${ }^{8,9}$ Despite the fact that COVID19 had an effect on almost every continent on the planet, climatic conditions played a significant role in determining the pandemic's global impact, taking into account the unique characteristics of each region. ${ }^{10}$ However, regardless of race or age, the disease's symptoms were the same. Death rates were being reported at breakneck pace in the newspapers, making it an especially trying time in human history. ${ }^{11}$

COVID-19's rapid spread is being investigated at all levels of human endeavor due to its grave consequences for all people affected across the world. The spread of COVID-19 is now relentless in almost all the countries of the world including Nigeria, causing serious public health, social and economic upheaval. $^{12-14}$ The mere surface of this pandemic, defying all scientific prowess, has plunged the entire planet into chaos. ${ }^{15}$ This conundrum necessitates a well-defined sequence and methodology that allows for adequate documentation of those impacted at all levels by the disease's global impact. This, too, necessitates a strategic approach, especially in the case of disadvantaged groups of all kinds. ${ }^{16}$ Data have it that millions of people are still dying daily irrespective of the availability of the World Health Organisation COVID-19 vaccine endorsement. The COVID-19 pandemic has created a new reality in which people are confronted with a previously unknown disease and its consequences, providing a unique opportunity to study vaccine attitudes at a time when disease awareness is high. ${ }^{17}$

Vaccines are the most important public health measure $^{18}$ and most effective strategy for controlling diseases in many countries around the world. ${ }^{19,20}$ Moreover, the distribution of vaccines is highly significant in order to analyze community acceptance of COVID-19 vaccines. ${ }^{21}$ All these call for a concerted effort to arrest the pandemic.
Hence, there is a need to encourage the COVID-19 vaccination to reduce the propagation rate.

Ironically, the fear of death arising from COVID-19 disease and other controversies surrounding the vaccine safety in different parts of the world has increased fears in many Nigerians recently. Unfortunately, the approved COVID-19 vaccine seems not to guarantee safety as many have anticipated. It seems many people are not too eager to be vaccinated owing to the acclaimed side effects some health tips suggest such as myocarditis and Pericarditis associated with Pfizer and Moderna vaccine.

Consequently, spread of messages by the media ${ }^{22-24}$ through multiple channels ${ }^{25}$ have deliberately tried to douse fears and uncertainty regarding the vaccine safety. People tend to be more careful especially with the news of health complications resulting from those who have already taken the COVID-19 vaccine, especially the speculations that the vaccine alters ones "DNA". ${ }^{26}$ This is in addition to social media videos demonstrating the magnetic and lighting potency of vaccines if injected area of someone is touched with metal or electric bulb as the case may be. Similarly, effective communication to create confidence and reduce public ambiguity is critical for promoting vaccination acceptability, willingness, and uptake, avoiding vaccine hesitancy, and dealing with any infodemic on the topic, such as in the case of COVID-19 vaccines. ${ }^{27-32}$ has turned out to be unsuitable in addressing the issue. More so, it appears the body language of many Nigerians show likelihood and tendency of rejecting the vaccine even if it is made compulsory by the government. ${ }^{33}$ Researchers have adduced reasons behind spreading of rumors, fake news, refusal of vaccine acceptance and vaccine hesitancy globally with regard to COVID-19 vaccine. ${ }^{34-38}$ Thus, reasons such as: Vaccine susceptibility, risk perception, and reaction ${ }^{39-44}$ certain religious beliefs, lack of knowledge and awareness. ${ }^{45-49}$ Likewise other reasons from Nigeria setting and other countries, such as poor health literacy ${ }^{50,51}$ conflicts and insecurities, ${ }^{52}$ distrust in governments and firms that manufacture the vaccines ${ }^{49,53-59}$ remain a serious challenge.

There seems to be obvious speculation suggesting that many people in South-east geo-political zone still doubt the integrity of the COVID-19 vaccine in circulation currently. Respondents in this terrain still think of COVID-19 as propaganda. The vaccine is often referred to as a "trial vaccine" by many people. ${ }^{11}$ The current status of Nigeria health care delivery discourages her citizens from even trusting on the integrity of the COVID-19 vaccine. Past research efforts indicated that people's reluctance to receive the vaccine 
was caused by their anxiety and uncertainty about it. $^{41,49,57,60-62}$ Future health education initiatives should focus on enhanced understanding about COVID-19 via mass media messaging and cues from health-care practitioners' recommendations to promote vaccine uptake by identifying a determinant that influences the intention to have the COVID-19 immunization. 59,63,64

\section{Materials and Methods}

A cross-sectional descriptive study was conducted among 399 respondents (18-47 years) in both urban and rural communities of Enugu State, Ebonyi State and Anambra State in South East region Nigeria from May 6th, to July 4th, 2021. The survey was carried out using structured questionnaire containing the respondents' demographics, knowledge and attitudes towards media messages regarding COVID-19 vaccine safety. The Online Scientific sample size determination Australian calculator was used to select the sample size of 399 .

\section{Measurement}

The data were analysed using the SPSS version 26 software. Result was presented on frequency tables, percentage and charts showing the interrelatedness of the variables examined. Regression ANOVA was used to test hypotheses on the extent to which the level of exposure to COVID-19 media messages predict their knowledge and attitude towards COVID-19 vaccine safety at $P<0.05$ level of significance.

\section{Result}

The result of the study as presented in Table 1 shows the distribution of respondents by age, gender, religion, educational qualification and occupation. Result shows that majority of the respondents were between the age range of 28-37 representing $47.9 \%$, while those within the age range of 18 27 and $38-47$ were represented by $26.6 \%$ and $25.6 \%$, respectively. Result also shows that $60.9 \%$ of the respondents are male while $39.1 \%$ are female. Also, result shows that $94.5 \%$ of the respondents were Christians while only $5.5 \%$ were Muslims. The reason for the high number of Christians is due partly to the fact that the area in which the study was carried out is dominated by Christian religion. On Qualifications, result shows that $26.6 \%$ are holders of B. Sc, $57.9 \%$ are with M.Sc while $15.5 \%$ are Ph.D holders. On Occupation, $26.6 \%$ are working class people, $16 \%$ are business men and women, $10.3 \%$ are unemployed while $47.1 \%$ of the respondents are students.
Table I Demographic Information of Respondents

\begin{tabular}{|l|c|c|c|}
\hline \multicolumn{2}{|c|}{} & Frequency & Percentage \\
\hline \multirow{2}{*}{ Age (in years) } & $18-27$ & 106 & 26.6 \\
& $28-37$ & 191 & 47.9 \\
& $38-47$ & 102 & 25.6 \\
& 48 Yrs and above & - & - \\
\hline \multirow{2}{*}{ Gender } & Male & 243 & 60.9 \\
& Female & 156 & 39.1 \\
\hline \multirow{2}{*}{ Religion } & Christianity & 377 & 94.5 \\
& Islam & 22 & 5.5 \\
\hline \multirow{2}{*}{ Qualification } & SSCE & - & - \\
& B.Sc & 106 & 26.6 \\
& M.Sc & 231 & 57.9 \\
& Ph.D & 62 & 15.5 \\
\hline \multirow{2}{*}{ Occupation } & Working Class & 106 & 26.6 \\
& Business Person & 64 & 16.0 \\
& Unemployed & 41 & 10.3 \\
& Student & 188 & 47.1 \\
\hline
\end{tabular}

\section{Respondents Level of Exposure to Media Messages on COVID-I 9 Vaccine Safety in South East, Nigeria How Would You Rate the Media
Messages on COVID-I 9 Vaccine?}

Result in Figure 1 shows the respondents' rating on media messages on COVID-19 vaccine safety. Result shows that $42 \%$ of the respondents rated the media message on COVID-19 vaccine safety as moderate, $32 \%$ rated it as very well, $21 \%$ rated adequate while only $5 \%$ were ignorant (ie, having no knowledge of media messages on COVID-19 vaccine safety. The finding of the study therefore shows that about $95 \%$ of the respondents are exposed media messages on COVID-19 vaccine safety in South east, Nigeria.

\section{What Risks of COVID-I 9 Vaccine Threatens You Most?}

Result on Table 2 shows that majority of the respondents are threatened on COVID-19 vaccine because of slow recovery $(64.9 \%)$, while $24.8 \%$ are threatened because of death complications and $10.3 \%$ of the respondents are threatened because of lack of hospital incentives. This implies that the respondents are exposed to media messages on COVID-19 


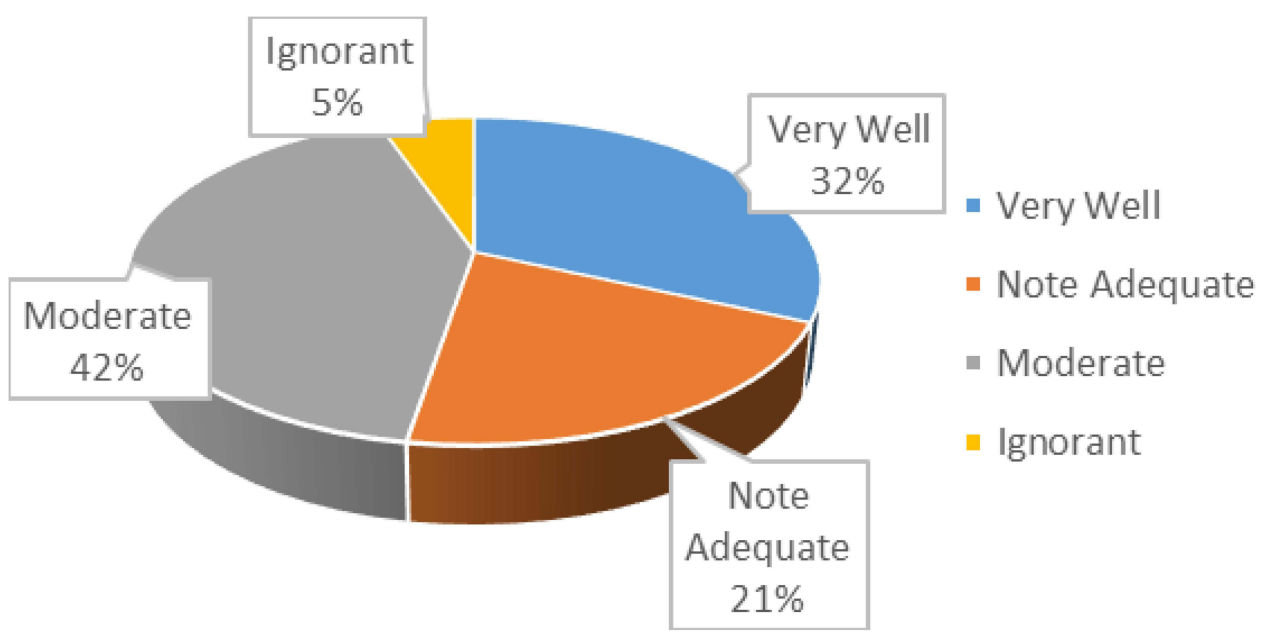

Figure I Pie chart showing respondents' rating of media messages on COVID-19 vaccine safety.

Vaccine safety but are threatened by death complications, slow recovery and no hospital incentives.

\section{How Frequent Do You Get Messages on COVID- 19 Vaccine?}

The result in Figure 2 shows that $37.1 \%$ of the respondents get media messages on COVID-19 vaccine regularly, $47.1 \%$ get it occasionally while $15.8 \%$ get media messages on COVID-19 Vaccine safety rarely. This implies that majority of the respondents are exposed to media messages on COVID-19 vaccine safety.

\section{How Would You Score Media Commitment to COVID-19 Vaccine Messages?}

Result on Figure 3 shows that $11 \%$ of the respondents rated media commitment to COVID-19 vaccine messages as excellent, $26 \%$ rated it as very good, $42 \%$ rated it as moderated and $21 \%$ rated media commitment to COVID19 vaccine messages as poor. These ratings indicate that

Table 2 Frequency and Percentages of Respondents' Responses on Risks of COVID-19 Vaccine

\begin{tabular}{|l|c|c|c|}
\hline S/N & Responses & Frequency & Percentage \\
\hline I & Death complications & 99 & 24.8 \\
2 & Slow recovery & 259 & 64.9 \\
3 & No hospital incentives & 4 I & 10.3 \\
& Total & 399 & $100.0 \%$ \\
\hline
\end{tabular}

the respondents are exposed to media messages on COVID-19 vaccine safety.

\section{What Media Platform Do You Get COVID-19 Vaccine More?}

Result on Table 3 shows that $26.3 \%$ of the respondents get COVID-19 vaccine messages through the radio, $21.8 \%$ get through Television (TV), 35.3\% get the messages through social media and $16.5 \%$ get the messages through friends and family. This result shows that respondents are exposed to media messages on COVID-19 vaccine safety.

\section{Do You Think Media Messages on COVID- 19 Vaccine is Very Assuring and Convincing Human Safety?}

Result on Table 4 shows that $26.1 \%$ of the respondents agreed that media messages on COVID-19 vaccine is very assuring and convincing as regards human safety; $42.4 \%$ disagreed on the safety of COVID-19 vaccine messages; $26.1 \%$ rated COVID-19 vaccine messages as moderate as regards human safety while $5.5 \%$ rated the vaccine messages as poor. Based on the responses, it is obvious that the respondents are exposed to media messages on COVID-19 vaccine safety.

\section{Do You Think Medical Personnel's in Nigeria are Well Equipped to Handle Patients While Injecting Them with the COVID- I 9 Vaccine?}

The result in Figure 4 shows that $48.4 \%$ of the respondents disagreed that medical personnel in Nigeria are well 


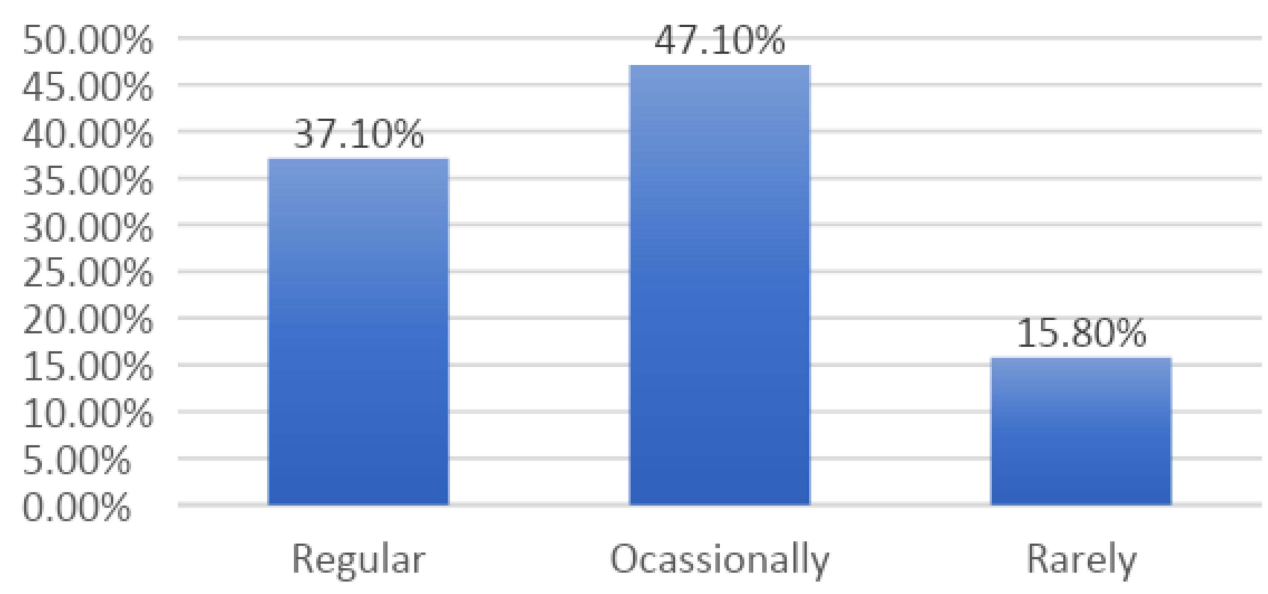

Figure 2 Bar chart showing the frequency of media messages on COVID-19 vaccine safety.

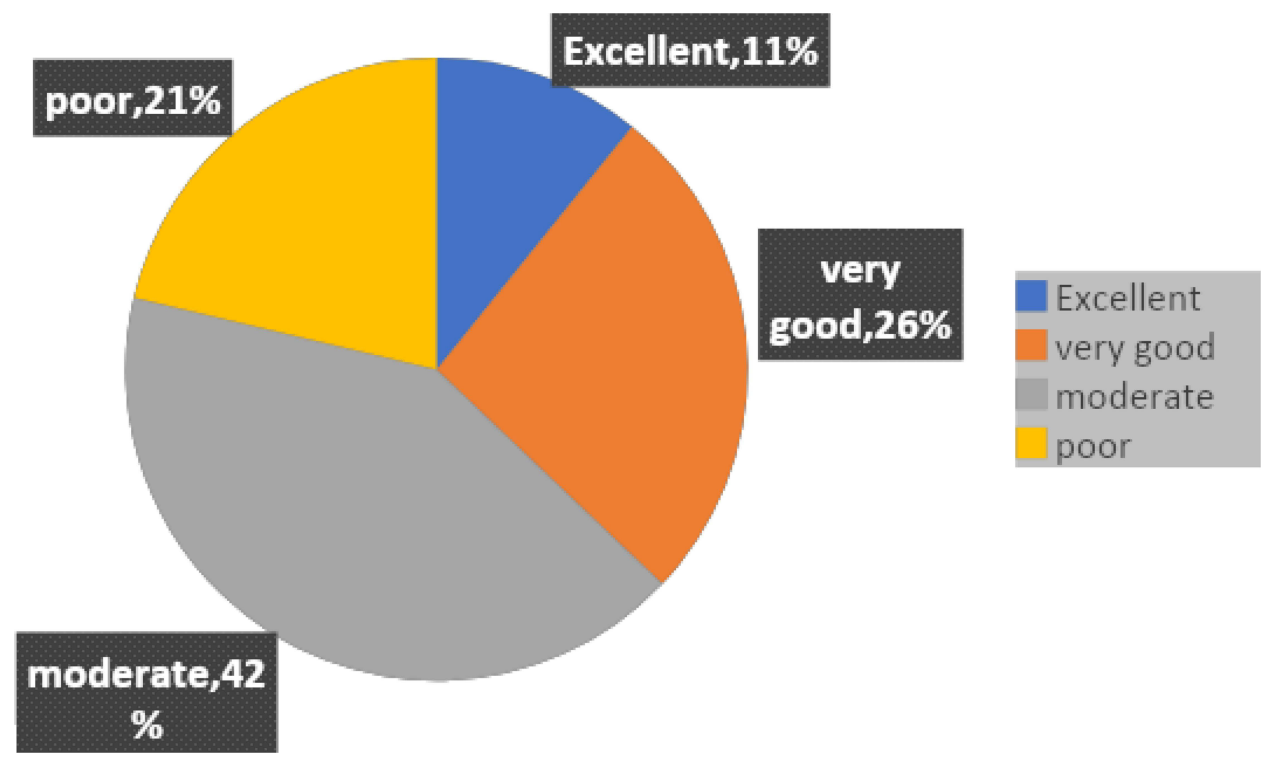

Figure 3 Pie chart showing media commitment to COVID-19 vaccine messages.

equipped to handle patients while injecting them with the COVID-19 vaccine; $30.6 \%$ are skeptical, $10.5 \%$ of the respondents agreed that medical personnels in Nigeria are well equipped to handle patients while injecting them with the COVID-19 vaccine while $10.5 \%$ rated medical personnel as being very poor with regard to whether they are well equipped to handle patients while injecting them with the COVID-19 vaccine. One can conclude from the ratings that the respondents are exposed to media messages on COVID-19 safety messages.

\section{Knowledge on COVID - I9 Vaccine Safety}

The result of the study on Table 5 shows that majority of the respondents $(53.1 \%)$ did not know about the safety of the COVID-19 vaccine while $36.1 \%$ of the respondents are not sure of the safety of the vaccine and only $10.8 \%$ of the respondents know about the safety of COVID-19 vaccine. On whether the respondents know anything about efficacy of the COVID-19 vaccine, $21.6 \%$ said Yes, $42.4 \%$ said No while $36.1 \%$ are not sure. On whether the respondents know COVID-19 vaccine have side effect, $52.9 \%$ said yes, $26.6 \%$ said no and $20.6 \%$ of the respondents are not sure. Also, on whether the COVID-19 vaccine has different versions, $47.6 \%$ said Yes it has, $29.6 \%$ said No it has no different versions and $22.8 \%$ are not sure yet. Finally, on whether the respondents know that the government can mandate citizens to be vaccinated, $10.8 \%$ said yes, $84.2 \%$ said no that the government should not mandate citizens to take the vaccine and $5 \%$ are not sure. Based on the 
Table 3 Percentages of Respondents on Media Platform COVID19 Vaccine Messages are Gotten

\begin{tabular}{|l|c|c|c|}
\hline S/N & Responses & Frequency & Percentage \\
\hline $\mathrm{I}$ & Radio & 105 & 26.3 \\
2 & TV & 87 & 21.8 \\
3 & Social media & 141 & 35.3 \\
4 & Friends and Family & 66 & 16.5 \\
& Total & 399 & $100.0 \%$ \\
\hline
\end{tabular}

Table 4 Percentages of Respondents on Whether Media Messages on COVID-19 Vaccine is Very Assuring and Convincing as Regards Human Safety

\begin{tabular}{|l|c|c|c|}
\hline S/N & Responses & Frequency & Percentage \\
\hline 1 & Yes & 104 & 26.1 \\
2 & No & 169 & 42.4 \\
3 & Moderate & 104 & 26.1 \\
4 & Poor & 22 & 5.5 \\
& Total & 399 & $100.0 \%$ \\
\hline
\end{tabular}

findings of this study, there is indication that the respondents have little knowledge of COVID-19 vaccine safety. The overall finding of the study shows that $28.72 \%$ of the respondents are knowledgeable about COVID-19 vaccine safety, $47.17 \%$ of the respondents have no knowledge about the vaccine safety and $24.11 \%$ of the respondents are not sure yet. This implies that the knowledge level of respondents on the safety of COVID-19 vaccine is low.

\section{Attitudes Towards COVID- I 9 Safety Vaccine Messages}

The result of the study on Table 6 shows that $16 \%$ of the respondents said the vaccine should be made compulsory by the government, $63.4 \%$ said no, while $20.6 \%$ are not sure. On whether the respondents think their family members should be vaccinated, $16 \%$ said yes, $67.2 \%$ said no, while $16.8 \%$ are not sure. Result also shows that $20.6 \%$ of the respondents said that COVID-19 vaccine have cultural implications, $32.3 \%$ said no, while $47.1 \%$ of the respondents are not sure about the cultural implication of the vaccine. On whether religious belief of the respondents contradicts COVID-19 vaccination, 5.3\% said yes, 79.4\% said no and $15.3 \%$ are not sure. Lastly, $21.6 \%$ of the respondents said yes that they will like to encourage their friends to take the COVID-19 vaccine, 58.1\% said no while $20.3 \%$ of the respondents are not sure whether they will like to encourage their friends to take the COVID-19 vaccine. Result on attitude of respondents towards the safety of COVID-19 vaccine, $15.89 \%$ of the respondents said yes, they think the vaccine is safe, $60.10 \%$ said no, they think the vaccine is not safe and $24.01 \%$ of the respondents are not sure. Based on the findings of this study, the researchers conclude that the respondents think COVID-19 vaccine is not safe.

\section{Hypotheses}

$\mathrm{Ho}_{1}$ : Respondents' level of exposure to COVID-19 media messages will not significantly predict their knowledge on COVID-19 vaccine safety.

Result on whether the respondents' level of exposure to COVID-19 media messages will not significantly predict their knowledge on COVID-19 vaccine safety showed that an f-ratio of $(F(1,398)=67.77, p=0.00)$ was obtained. Since the associated probability value (p-value) of 0.00 is

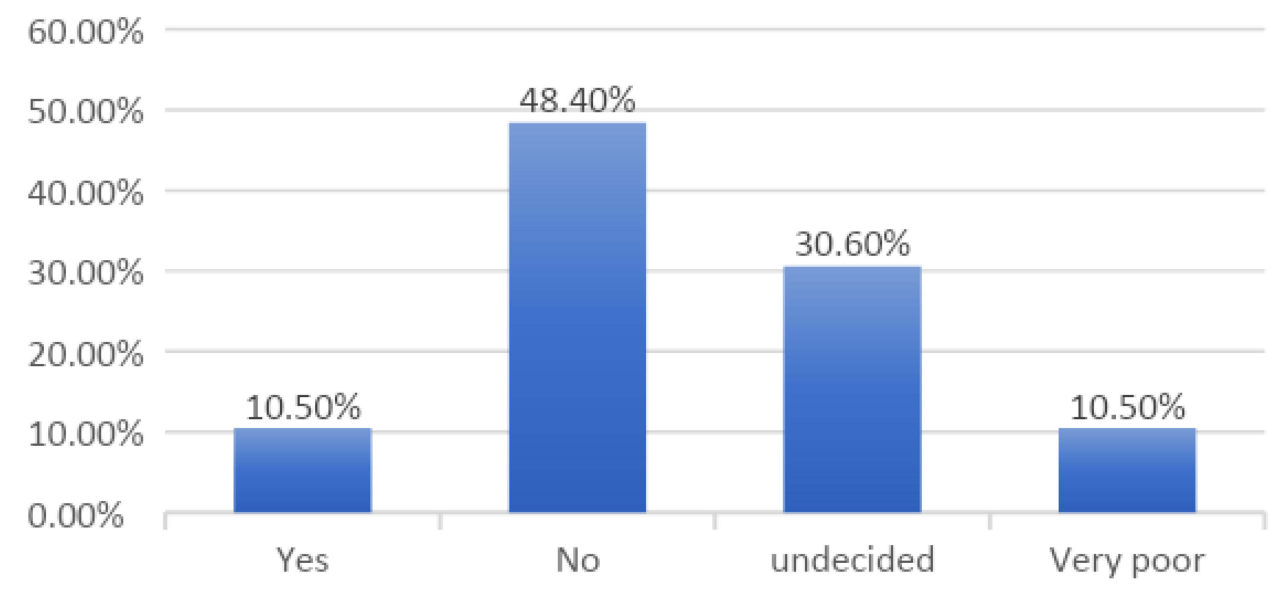

Figure 4 Bar chart showing the responses of respondents on whether medical personnel in Nigeria are well equipped to handle patients while injecting them with the COVID-19 vaccine. 
Table 5 Frequency and Percentages of Respondents on COVID-I9 Vaccine Safety

\begin{tabular}{|c|c|c|c|c|c|c|c|}
\hline \multirow[t]{2}{*}{$\mathbf{S} / \mathbf{N}$} & \multirow[t]{2}{*}{ Statements } & \multicolumn{2}{|c|}{ Yes } & \multicolumn{2}{|c|}{ No } & \multicolumn{2}{|c|}{ Not Sure } \\
\hline & & Freq. & $\%$ & Freq. & $\%$ & Freq. & $\%$ \\
\hline 1 & Do you know about the safety of COVID-I9 vaccine? & 43 & 10.8 & 212 & 53.1 & 144 & 36.1 \\
\hline 2 & Do you know anything about the efficacy of the vaccine? & 86 & 21.6 & 169 & 42.4 & 144 & 36.1 \\
\hline 3 & Do you know COVID-19 vaccine have side effects? & 211 & 52.9 & 106 & 26.6 & 82 & 20.6 \\
\hline 4 & Do you know the vaccine have different versions? & 190 & 47.6 & 118 & 29.6 & 91 & 22.8 \\
\hline \multirow[t]{2}{*}{5} & Do you know government can mandate citizens to be vaccinated? & 43 & 10.8 & 336 & 84.2 & 20 & 5.0 \\
\hline & Total & 573 & 28.72 & 941 & 47.17 & 481 & 24.1I \\
\hline
\end{tabular}

Table 6 Frequency and Percentages of Respondents' Attitude Towards COVID-19 Vaccine Safety

\begin{tabular}{|c|c|c|c|c|c|c|c|}
\hline \multirow[t]{2}{*}{$\mathbf{S} / \mathbf{N}$} & \multirow[t]{2}{*}{ Statements } & \multicolumn{2}{|c|}{ Yes } & \multicolumn{2}{|c|}{ No } & \multicolumn{2}{|c|}{ Not Sure } \\
\hline & & Freq. & $\%$ & Freq. & $\%$ & Freq. & $\%$ \\
\hline 1 & $\begin{array}{l}\text { Do you think the vaccine should be made compulsory by the } \\
\text { government? }\end{array}$ & 64 & 16.0 & 253 & 63.4 & 82 & 20.6 \\
\hline 2 & Do you think your family members should be vaccinated? & 64 & 16.0 & 268 & 67.2 & 67 & 16.8 \\
\hline 3 & Do you think COVID-19 vaccine have cultural implication? & 82 & 20.6 & 129 & 32.3 & 188 & 47.1 \\
\hline 4 & $\begin{array}{l}\text { Do you feel your religious belief contradict COVID-I9 } \\
\text { vaccination? }\end{array}$ & 21 & 5.3 & 317 & 79.4 & 61 & 15.3 \\
\hline \multirow[t]{2}{*}{5} & $\begin{array}{l}\text { Would you like to encourage your friends to take the COVID-I9 } \\
\text { Vaccine? }\end{array}$ & 86 & 21.6 & 232 & 58.1 & 81 & 20.3 \\
\hline & Total & 317 & I5.89 & 1199 & 60.10 & 479 & 24.01 \\
\hline
\end{tabular}

less than 0.05 level of significance at which the result is being tested, the null hypothesis is not accepted and inference drawn is that respondents' level of exposure to COVID-19 media messages is a significant predictor of their knowledge on COVID-19 vaccine safety. This means that exposure to COVID-19 media messages can significantly predict the extent to which the masses will accept that COVID-19 vaccine is safe.

$\mathrm{Ho}_{2}$ : Respondents' level of exposure to COVID-19 media messages will not significantly predict their attitude towards COVID-19 vaccine safety.

In order to test hypothesis two, result shows that an f-ratio of $(F(1,398)=19.67, p=0.00)$ was obtained. Since the associated probability value (p-value) of 0.00 is less than 0.05 level of significance set for testing the hypothesis, this means that the null hypothesis is not accepted. Inference drawn therefore is that respondents' level of exposure to
COVID-19 media messages is a significant predictor of their attitude towards COVID-19 vaccine safety. This equally implies that exposure to COVID-19 vaccine safety media messages can significantly predict attitude of masses towards accepting that COVID-19 vaccine is safe.

\section{Discussion}

The study aimed at assessing the knowledge and attitude of residents of south-east, Nigeria towards COVID-19 vaccine safety. Results show that majority (95\%) of the respondents were exposed to media messages on COVID19 vaccine safety in varying degrees in South east, Nigeria. While $42 \%$ were moderately exposed, $32 \%$ were well exposed and $21 \%$ were adequately exposed to the vaccine safety messages. Only $5 \%$ of the respondents were ignorant of the messages.

Findings of the current study regarding the source of exposure indicate that majority of the respondents were 
exposed to vaccine safety messages through the social media $35 \%$, radio $26.3 \%$, television $21.8 \%, 16.5 \%$ of the respondents who were exposed to COVID-19 vaccine safety messages through friends and families. The reason for social media been the dominant sources of the vaccine messages is not farfetched bearing in mind the popularity of the social media for information dissemination in contemporary times. The study also collaborates with the study of Zeballos et $\mathrm{al}^{44}$ which found that social media exposure to COVID-19 information influences the adoption of preventive attitudes and behaviors through shaping risk perception.

This is in contrast with the study conducted by AlMarshoudi et $\mathrm{al}^{25}$ in Omani community's which found that their willingness to take COVID-19 vaccine can be enhanced by utilizing social media and community influencers to spread awareness about the vaccine's safety and efficacy. The result of this study indicates that the knowledge level of respondents on the safety of COVID-19 vaccine is low. Only $28.72 \%$ of the respondents are knowledgeable about COVID-19 vaccine safety messages. Respondents' level of exposure to COVID-19 media messages is a significant predictor of their knowledge on COVID-19 vaccine safety. The study is similar to the findings of Islam et $\mathrm{al}^{20}$ that indicated inadequate knowledge but more positive attitudes towards COVID-19 vaccine among the general population in Bangladesh. Also, another study by Mesesle $^{3}$ in Ethiopia indicated poor knowledge towards COVID-19 vaccine. This means that exposure to COVID-19 media messages can significantly predict the extent of respondents' knowledge towards the safety of COVID-19 vaccine.

The findings on attitude of the respondents towards the safety of COVID-19 vaccine show that majority of the respondents $(60.10 \%)$ think that the vaccine is not safe. Respondents' level of exposure to COVID-19 media messages is a significant predictor of their attitude towards COVID-19 vaccine safety. This equally implies that exposure to COVID-19 media messages can significantly predict attitude of respondents towards COVID-19 vaccine safety. The study is in agreement with Fridman et al ${ }^{17}$ study that found a decline in general vaccine attitudes and intentions of getting the influenza vaccine. In addition, certain characteristics of the COVID-19 vaccines themselves like efficacy, safety, and side effects influence public attitudes. ${ }^{38}$

\section{Conclusion}

Knowledge regarding media messages on COVID-19 vaccine safety is low. Messages on COVID-19 vaccine safety were not sufficient and convincing. Consequently, there is a negative attitude towards the vaccine. Respondents' level of exposure to COVID-19 media messages is a significant predictor of their knowledge and attitude on COVID-19 vaccine safety. Hence, improving knowledge and adoptive attitude amongst respondents amidst COVID-19 is critical.

\section{Data Sharing Statement}

The data presented in this work are with the authors and will be made available on request.

\section{Ethics Approval and Consent to Participate}

Ethical clearance was obtained from the Faculty of Arts Research Ethics Committee University of Nigeria, Nsukka with reference No UN/FA/FAREC/02232021. All participants involved in this study were 18 years and above, and provided written informed consent in accordance with the declaration of Helsinki.

\section{Acknowledgments}

The authors would like to thank all participants involved in this study.

\section{Author Contributions}

All authors contributed significantly to the work and have agreed on the journal to which the article will be submitted, gave final approval of the version to be published, and agreed to be accountable for all aspects of the work.

\section{Disclosure}

The authors report no conflicts of interest in this work.

\section{References}

1. Andersen KG, Rambaut A, Lipkin WI, et al. The proximal origin of SARS-COVID-2. Nat Med. 2020;26(4):450-452. doi:10.1038/s41591020-0820-9

2. Al- Hanawi KM, Angwi K, Alshareef N, et al. Knowledge, attitude and practice toward COVID-19 among the public in the Kingdom of Saudi Arabia: a cross-sectional study. Front Public Health. 2020;8:217. doi:10.3389/fpubh.2020.00217

3. Mesesle M. Awareness and attitude towards COVID-19 vaccination and associated factors in Ethiopia: cross-sectional study. Infect Drug Resist. 2021;14:2193-2199. doi:10.2147/IDR.S316461

4. Huang C, Wang Y, Li X, et al. Clinical features of patients infected with 2019 novel coronavirus in Wuhan, China. Lancet. 2020;395:497-506. doi:10.1016/S0140-6736(20)30183-30

5. Jaber RM, Mafrachi B, Al-Ani A, Shkara M, Tu W-J. Awareness and perception of COVID-19 among the general population: a Middle Eastern survey. PLoS One. 2021;16(4):1-10. doi:10.1371/journal. pone. 0250461 
6. Lucero-Prisno DE, Adebisi YA, Lin X. Current efforts and challenges facing responses to 2019-nCoV in Africa. Glob Health Res Policy. 2020;5:21. doi:10.1186/s41256-020-00148-1

7. Ogunkola IO, Adebisi YA, Imo UF, et al. Rural communities in Africa should not be forgotten in responses to COVID-19. Int J Health Plann Manag. 2020;35(6):1302-1305. doi:10.1002/ hpm.3039

8. Mueller AL, McNamara MS, Sinclair DA. Why does COVID-19 disproportionately affect older people? Aging (Albany NY). 2020;12 (10):9959-9981. doi:10.18632/aging.103344

9. Wang C, Horby PW, Hayden FG, et al. A novel outbreak of global health concern. Lancet Microbe. 2020;390:1-4. doi:10.1016/S01406736(20)30185-9.

10. Africa Center for Disease Control (ACDC). (COVID-19) research and development priorities for COVID-19 in Africa. Policy paper; 2020. Available from https://africacdc.org/download/policy-paperresearch-and-development-priorities-for-covid-19-in-africa/\#. Accessed March 6, 2021.

11. World Health Organisation. Teleconference of the R \& D Blueprint GMC. Pneumonia of unknown etiology in Wuhan China. January 20, 2020. Available from: https://www.who.int/publications $/ \mathrm{m} /$ item $/ \mathrm{gcm}$ teleconference-on-pneumonia-of-unknown-etiology-in-wuhan-chinanote-for-the-records. Accessed March 4, 2021.

12. World Health Organisation. Novel Corona virus. (2019-Ncov) situation report-1. World Health Organization; January 21, 2020. Available from https://apps.who.int/iris/handle/10665/330760. Accessed March 5, 2021.

13. Dutta AK. Vaccine against COVID-19 disease - present status of development. Indian J Pediatr. 2020;87(10):810-816. doi:10.1007/ s12098-020-03475-w

14. Adebowale AS, Fagbamigbe AF, Akinyemi JO, et al. The spread of COVID-19 outbreak in the first 120 days: a comparison between Nigeria and seven other countries. BMC Public Health. 2021;21:129. doi:10.1186/s12889-020-10149-x

15. Burrell C, Howard CR, Murphy F. Fenner and White's Medical Virology. 5th ed. United States: Academic Press; 2016.

16. Bao L, Deng W, Gao H, et al. Reinfection could not occur in SARS COV-2 infected rhesus Macaques. BioRxiv. 2020. doi:10.1101/ 2020.03.13.990226

17. Fridman A, Gershon R, Gneezy A, Capraro V. COVID-19 and vaccine hesitancy: a longitudinal study. PLoS One. 2021;16(4): e0250123. doi:10.1371/journal.pone.0250123

18. Wani RT, Dar H, Raina ZA. Knowledge, attitude and practices of mothers with children under five years of age about vaccination. J Med Sci Clin Res. 2017;5:24449-24454. doi:10.18535/jmscr/ v5i7.22

19. Sunny A, Ramesh S, Shankar BK. A study to assess and correlate the knowledge, attitude and practices of vaccination among mothers with educational status in a Teaching Hospital in South India. Prim Health Care. 2018;8:1-6. doi:10.4172/2167-1079.1000290

20. Islam MS, Siddique AB, Akter R, et al. Knowledge, attitudes and perceptions towards COVID-19 vaccinations: a cross-sectional community survey in Bangladesh. medRxiv. 2021. doi:10.1101/ 2021.02.16.21251802

21. Reiter PL, Pennell ML, Katz ML. Acceptability of a COVID-19 vaccine among adults in the United States: how many people would get vaccinated? Vaccine. 2020;38:6500-6507. doi:10.1016/j. vaccine.2020.08.043

22. Daley MF, Narwaney KJ, Shoup JA, et al. Addressing parents' vaccine concerns: a randomized trial of a social media intervention Am J Prev Med. 2018;55(1):44-54. doi:10.1016/j.amepre. 2018.04.010

23. Arede M, Bravo-Araya M, Bouchard E, et al. Combating vaccine hesitancy teaching the next generation to navigate through the post truth era. Front Public Health. 2018;6:381. doi:10.3389/ fpubh.2018.00381
24. Dube E, Vivion M, MacDonald NE. Vaccine hesitancy, vaccine refusal and the anti-vaccine movement: influence, impact and implications. Expert Rev Vaccines. 2015;14(1):99-117. doi:10.1586/ 14760584.2015.964212

25. Al-Marshoudi S, Al-Balushi H, Al-Wahaibi A, et al. Knowledge, Attitudes, and Practices (KAP) toward the COVID-19 vaccine in Oman: a pre-campaign cross-sectional study. Vaccines. 2021;9 (6):602. doi:10.3390/vaccines9060602

26. Olufemi OE, Kikelomo OW, Anya SA, et al. Predictors of COVID-19 information sources and their perceived accuracy in Nigeria: online cross-sectional study. JMIR Public Health Surveill. 2021;7(1). doi:10.2196/22273

27. Bostrom A. "Vaccine risk communication: lessons from risk perception, decision making and environmental risk communication research (1990-2002). RISK Health Saf Environ. 1997;8(2):173.

28. Downs JS, Bruine de Bruin W, Fischhoff B. Parents' vaccination comprehension and decisions. Vaccine. 2008;26(12):1595-1607. doi:10.1016/j.vaccine.2008.01.011

29. Holt DF, Bouder C, Elemuwa G, et al. The importance of the patient voice in vaccination and vaccine safety are we listening?". Clin Microbiol Infect. 2016;22:S146-S153. doi:10.1016/j. cmi.2016.09.027

30. Krause NM, Freiling I, Beets B, et al. Fact-checking as risk communication: the multi-layered risk of misinformation in times of COVID-19.”. J Risk Res. 2020;23(7-8):1052-1059. doi:10.1080/ 13669877.2020 .1756385

31. Warren GW, Lofstedt R. COVID-19 vaccine rollout risk communication strategies in Europe: a rapid response. J Risk Res. 2021;24(34):369-379. doi:10.1080/13669877.2020.1870533

32. Eniade DO, Olarinmoye A, Otovwe A, et al. Willingness to accept COVID-19 vaccine and its determinants among Nigeria citizens: a web-based cross-sectional study. J Adv Med Med Res. 2021;33 (8):13-22. doi:10.9734/jammr/2021/v33i830881

33. World Health organisation. GMC Teleconference. Note for records. Subject: pneumonia in Wuhan China; January 10, 2020. Available from https://www.who.int/publications/m/item/gcm-teleconferenceon-pneumonia-of-unknown-etiology-in-wuhan-china-note-for-therecords-10-january-2020. Accessed March 4, 2021.

34. Lane S, MacDonald NE, Marti M, et al. Vaccine hesitancy around the globe: analysis of three years of WHO/UNICEF Joint Reporting Form data-2015-2017. Vaccine. 2018;36:3861-3867. doi:10.1080/ 13669877.2020.1756385

35. Wagner AL, Masters NB, Domek GJ, et al. Comparisons of vaccine hesitancy across five low- and middle-income countries. Vaccines. 2019;7(4):155. doi:10.3390/vaccines7040155

36. The Lancet Child \& Adolescent Health. Vaccine hesitancy: a generation at risk. Lancet Child Adolesc Health. 2019;3:281. doi:10.1016/S2352-4642(19)30092-6.

37. Elhadi M, Alsoufi A, Alhadi A. Knowledge, attitude, and acceptance of healthcare workers and the public regarding the COVID-19 vaccine: a cross sectional study. BMC Public Health. 2021;21:955. doi:10.1186/s12889-021-10987-3

38. Al-Jayyousi GF, Sherbash MAM, Ali LAM, et al. Factors influencing public attitudes towards COVID-19 vaccination: a scoping review informed by the socio-ecological model. Vaccines. 2021;9:548. doi:10.3390/vaccines 9060548

39. Wang J, Jing R, Lai Z, et al. Acceptance of COVID-19 vaccination during the COVID-19 pandemic in China. Vaccines. 2020;8:482. doi:10.3390/vaccines 8030482

40. Guidry JP, Laestadius LI, Vraga EK, et al. Willingness to get the COVID-19 vaccine with and without emergency use authorization. $\mathrm{Am}$ J Infect Control. 2021;49:137-142. doi:10.1016/j.ajic.2020.11.018

41. Detoc M, Bruel S, Frappe P, et al. Intention to participate in a COVID-19 vaccine clinical trial and to get vaccinated against COVID-19 in France during the pandemic. Vaccine. 2020;38 (45):7002-7006. doi:10.1016/j.vaccine.2020.09.04 
42. Harapan H, Wagner A, Yufika A, et al. Acceptance of a COVID-19 vaccine in Southeast Asia: a cross-sectional study in Indonesia. Front Public Health. 2020;8:381. doi:10.3389/fpubh.2020.00381

43. Lin Y, Hu Z, Zhao Q, et al. Understanding COVID-19 vaccine demand and hesitancy: a nationwide online survey in China. PLoS Negl Trop Dis. 2020;14:e0008961. doi:10.1371/journal.pntd.0008961

44. Zeballos DR, Jaldin ML, Canaviri BN, et al. Social media exposure, risk perception, preventive behaviors and attitudes during the COVID-19 epidemic in La Paz, Bolivia: a cross sectional study. PLoS One. 2021;16(1):e0245859. doi:10.1371/journal.pone.0245859

45. Karafillakis E, Larson HJ, Consortium A. The benefit of the doubt or doubts over benefits? A systematic literature review of perceived risks of vaccines in European populations. Vaccine. 2017;35:4840-4850. doi:10.1016/j.vaccine.2017.07.061

46. Pelcic G, Karacic S, Mikirtichan GL, et al. Religious exception for vaccination or religious excuses for avoiding vaccination. Croat Med J. 2016;57:516-521. doi:10.3325/cmj.2016.57.516

47. Yaqub O, Castle-Clarke S, Sevdalis N, et al. Attitudes to vaccination: a critical review. Soc Sci Med. 2014;112:1-11. doi:10.1016/j. socscimed.2014.04.018

48. Mannan KA, Farhana KM. Knowledge, attitude and acceptance of a COVID-19 vaccine. Int $R \quad J$ Bus Soc Sci. 2020;4(6):1-23. doi:10.2139/ssrn.3763373

49. Popa GL, Muntean AA, Muntean MM, et al. Knowledge and attitudes on vaccination in southern Romanians: a cross-sectional questionnaire. Vaccines. 2020;8(4):774. doi:10.3390/ vaccines 8040774

50. Biasio LR, Bonaccorsi G, Lorini C, Pecorelli S. Assessing COVID-19 vaccine literacy: a preliminary online survey. Hum Vaccines Immunother. 2021;17(5):1304-1312. doi:10.1080/ 21645515.2020.1829315

51. Danchin M, Biezen R, Manski-Nankervis JA, et al. Preparing the public for COVID-19 vaccines: how can general practitioners build vaccine confidence and optimise uptake for themselves and their patients? Aust J Gen Pract. 2020;49(10):625-629. doi:10.31128/ AJGP-08-20-5559

52. Adebisi YA, Alaran AJ, Bolarinwa OA, et al. When it is available, will we take it? Social media users' perception of hypothetical COVID-19 vaccine in Nigeria. Pan Afr Med J. 2021;38:230. doi:10.11604/pamj.2021.38.230.27325

53. Baumgaertner B, Carlisle JE, Justwan F, Rabinowitz M. The influence of political ideology and trust on willingness to vaccinate. PLoS One. 2018;13(1):e0191728. doi:10.1371/journal.pone.0191728
54. Pew Research Center. Public trust in government: 1958-2019. Pew Research Center; April 11, 2019. Available from: https://www.pewre search.org/politics/2019/04/11/public-trust-in-government-19582019/. Accessed January 2, 2021.

55. Lazarus JV, Ratzan SC, Palayew A, et al. A global survey of potential acceptance of a COVID-19 vaccine. Nat Med. 2021;27(2):225-228. doi:10.1038/s41591-020-1124-9

56. Fisher KA, Bloomstone SJ, Walder J, et al. Attitudes toward a potential SARS-CoV-2 vaccine: a survey of US adults. Ann Intern Med. 2020;173(12):964-973. doi:10.7326/M20-3569

57. Prati G. Intention to receive a vaccine against SARS-CoV-2 in Italy and its association with trust, worry and beliefs about the origin of the virus. Health Educ Res. 2020;35(6):505-511. doi:10.1093/her/ cyaa043

58. de Figueiredo A, Simas C, Karafillakis E, et al. Mapping global trends in vaccine confidence and investigating barriers to vaccine uptake: a large-scale retrospective temporal modelling study. Lancet. 2020;396(10255):898-908. doi:10.1016/S0140-6736(20) 31558-0

59. Jennings W, Stoker G, Bunting H. Lack of trust, conspiracy, beliefs, and social media use predict, COVID-19 vaccine hesitancy. Vaccines. 2021;9(6):593. doi:10.3390/vaccines9060593

60. Chen M, Li Y, Chen J. An online survey of the attitude and willingness of Chinese adults to receive COVID-19 vaccination. Hum Vaccines Immunother. 2021;17(7):2279-2288. doi:10.1080/ 21645515.2020.1853449

61. Akarsu B, Özdemir DC, Baser DA, et al. While studies on COVID19 vaccine is ongoing, the public's thoughts and attitudes to the future COVID-19 vaccine. Int J Clin Pract. 2020;75(4):e13891. doi:10.1111/ijcp.13891

62. Taylor S, Landry CA, Paluszek MM, et al. Proactive approach for managing COVID-19: the importance of understanding the motivational roots of vaccination hesitancy for SARS-CoV2. Front Psychol. 2020;17:2890. doi:10.3389/fpsyg.2020.575950

63. Huynh G, Tran TT, Nguyen HTN, et al. COVID-19 vaccination intention among healthcare workers in Vietnam. Asian Pac J Trop Med. 2021;4(4):159-164. doi:10.4103/1995-7645.312513.22

64. Al-Mohaithef M, Padhi BK. Determinants of COVID-19 vaccine acceptance in Saudi Arabia: a web-based national survey. $J$ Multidiscip Health. 2020;13:1657-1663. doi:10.2147/JMDH. S276771
Infection and Drug Resistance

\section{Publish your work in this journal}

Infection and Drug Resistance is an international, peer-reviewed openaccess journal that focuses on the optimal treatment of infection (bacterial, fungal and viral) and the development and institution of preventive strategies to minimize the development and spread of resistance. The journal is specifically concerned with the epidemiology of antibiotic resistance and the mechanisms of resistance development and diffusion in both hospitals and the community. The manuscript management system is completely online and includes a very quick and fair peerreview system, which is all easy to use. Visit http://www.dovepress.com/ testimonials.php to read real quotes from published authors. 